\title{
Espezúa Salmón, D. (2017). Las consciencias lingüísticas en la literatura peruana. Lima: CELACP - Lluvia - Latinoamericana.
}

La historia de la literatura peruana ha recurrido a la constitución lingüística de las obras para poder delimitar su campo de estudio. Lo encontramos desde Riva Agüero quien, en 1905, aceptaba que «la lengua constituye el único criterio, y nó meramente exterior» para definir su inclusión nacional. Dorian Espezúa, investigador sanmarquino, recoge ese interés para reorientar los estudios en el área, ampliando el criterio unitario del autor mencionado: al partir desde un reconocimiento de las 48 lenguas en el país, se cuestiona sobre la validez de todas ellas para la creación literaria en tanto los autores - consciente, inconsciente o no conscientemente- las ejerzan en el sistema en el que se insertan.

Esta variedad de lenguas coexiste conflictivamente $y$, durante el transcurso histórico de su reconocimiento, han generado momentos de alto vuelo creativo y reivindicativo. Así, la hipótesis que maneja Espezúa resalta esta idea:

Lo más original y representativo (no necesariamente lo más importante) de la literatura peruana ha surgido de los procesos de mezcla, superposición, criollización, transculturación, heterogeneidad, sincretismo o hibridez de las lenguas, géneros y culturas que conforman la cultura y literatura peruana. (23)

Es decir, el corpus de autores con los que dialogará el catedrático sanmarquino responde a una determinada expresión de los espacios nacionales, por lo que son escritores reconocidos y que, además, destacan por su experimentación con la lengua escogida para la escritura.

De esta manera, y valiéndose de conceptos de la literatura como sistema, periodo y evolución, y de la lingüística como bilingüismo y la diglosia, emprenderá el análisis de cada uno de ellos con el fin de rescatar las particularidades de sus producciones. Analizará, por tanto, sus textos de no-ficción, pues en ellos se pueden hallar explícita o implícitamente la consciencia personal acerca de la lengua y los procesos de escritura.

Dorian Espezúa realiza una clasificación doble para enmarcar su estudio. Por un lado, postula cinco proyectos lingüísticos alternativos: 1) Lengua normada, 2) Lengua española «peruanizada», 3) Lengua misturada o «kuika», 4) Lengua originaria y 5) Lengua extranjera. La elección de estos proyectos implica una preferencia por una o varias lenguas determinadas, la que variará de acuerdo con las condiciones del medio literario en el que se desenvuelven. Por otro lado, 
la división histórica destaca los «periodos en los que la lengua se hizo protagonista» (73), estableciendo así tres momentos: 1) Imposición del dominio y de la estabilización colonial, 2) Crisis del régimen colonial y de la república oligárquica y 3) Crisis del Estado oligárquico. Si bien estas divisiones pueden parecer esquemáticas, permiten comprender a rasgos generales el desarrollo de los diversos sistemas literarios que constituyen nuestra tradición.

Dentro del primer periodo ubica a dos paradigmas de los estudios coloniales. Para Felipe Guaman Poma de Ayala y su Nueva corónica postula la idea de que este es un texto trilingüe, pues recoge los discursos lingüísticos de, por lo menos, tres sujetos culturalmente distintos; además, es multisemiótico por su condición escrita y de escritura-dibujada; por último, un texto diglósico inestable. Para el caso del Inca Garcilaso de la Vega, plantea que sus Comentarios reales son textos metalingüísticos, pues en este libro se manifiesta su conocimiento pleno de las estructuras gramaticales del español, pero también del quechua, aunque sin ocultar su evidente diglosia en favor del primero, el cual responde al contexto del cual forma parte. Estos dos primeros autores marcan una pauta importante en el desarrollo de los diversos proyectos que ha dado cuenta el investigador, pues los conflictos que estos generan con la lengua se hacen manifiestos en autores como Gamaliel Churata, siglos después.

En la transición de la crisis colonial hacia la estabilización oligárquica sitúa a dos autores que, a juzgar por su legado intelectual, muestran proyectos paradójicos con sus propuestas y antagónicos en gran medida. Ricardo Palma, autor de las Tradiciones peruanas, quien nace junto al Perú recientemente independizado, impugna un lenguaje panhispanoamericano que, fundamentado en su conocimiento filológico y lexicográfico, incorpora al español léxicos americanos que no alteren su estructura gramatical, labor que no concilia con la idea de emancipación. González Prada, considerado el antihispano por excelencia, por otro lado, realiza un planteamiento en el que las lenguas indígenas son concebidas como un obstáculo a la propuesta de concebir un idioma propio que esté influenciado por el alemán, el inglés, el francés y el italiano. Estas construcciones paralelas muestran la divergencia de paradigmas escriturales que coexisten en un periodo determinado, pero también la dificultad en erigir un proyecto íntegro en un mismo personaje.

Como herederos de los conflictos lingüísticos expresados y de las creaciones literarias de los mismos, en esta tercera etapa se ubican a Gamaliel Churata y José María Arguedas, hombres andinos que, a pesar de su mestizaje, asumen la identidad indígena y, con ella, las posibilidades de una escritura que ubique lo nacional. 
El puneño autor de El pez de oro, fundamentando la idea de una literatura en el lenguaje principalmente, cuestionando la actitud de Garcilaso y asumiendo el legado de Guaman Poma, postula la lengua kuika, una construcción que incorpora al español, al aymara y al quechua como resultado de la convivencia de los tres factores del nuevo hombre americano. José María Arguedas, en una idea semejante, implementa un lenguaje literario que «mistura» el quechua y el español, otorgando un aporte mayor a las innovaciones formales de su narrativa. Ambos, sin embargo, obvian una gran parte de las lenguas existentes del total, no por deméritos que encuentren en ellas, sino por desconocimiento, con lo cual evitan traicionar su honradez intelectual.

Tal carencia llama la atención de Espezúa, por lo que intenta llenar estos vacíos a través de la encuesta a los autores nativos. A través de un análisis porcentual de los resultados consigue demostrar su hipótesis,

que el llamado sistema literario escrito en lenguas nativas está representado por escritores mestizos y bilingües con estudios superiores pertenecientes a la «ciudad letrada» que publican textos bilingües español-lengua indígena dirigidos a un público lector conformado por investigadores, especialistas o lectores letrados. (401)

El investigador no logra proponer salidas a las problemáticas que se observa luego de la revisión de resultados; sin embargo, su aporte radica en la apertura de estas interrogantes para empezar a desarrollar diversas estrategias que solucionen la carencia de sistemas literarios en lenguas nativas.

Este extenso estudio, producto de la tesis doctoral de Espezúa Salmón, resalta importantes composiciones en el proceso poético de los autores, como lo son los planteamientos lingüísticos. Este retorno a la lengua, es decir, al material primario con el que trabajan los escritores, forma parte de su proyecto particular de reorientación de los estudios literarios, en tanto considera para su corpus solo textos escritos antes que orales y autores caracterizados por su destacada labor en la ficción y estéticamente validados. Sin embargo, llama la atención el uso de escritores como el Inca Garcilaso y Guaman Poma, quienes no concibieron la idea de estar haciendo literatura. Más allá de estas posibles inconsistencias, rescatamos la apertura de nuevas líneas de investigación en literaturas nativas y su vínculo con la tradición como resultado al finalizar la lectura.

Álex Hurtado 